\title{
The influence of medical insurance and social security cards on the floating population's settlement intention
}

\author{
Yulin $\mathrm{Li}^{1 \dagger}$, Lingling Huang ${ }^{2 \dagger}$, $\mathrm{Li} \mathrm{Xiang}^{3}$ and Dongmei Dou ${ }^{1 *}$
}

\begin{abstract}
Background: Medical insurance and social security cards are an important incentive for the floating population to live a stable life in their current residence, but there has been little studies on their effect on settlement intentions. Therefore, the purpose of this paper was to study the impact of basic medical insurance for urban employees and application for personal social security cards on the settlement intentions of the floating population. With the increase of the desire to settle, the health management and the development of public health will be improved.

Methods: Based on the 2017 survey data from the dynamic monitoring of China's floating population, we explored the influence of basic medical insurance for urban employees and social security cards on the floating population's settlement intentions. Additionally, this study also examined the comprehensive causal relationship, with social integration as the mediator variable. We used SPSS 21.0 software. The input method was used to analyze the influence of the above variables by binary logistic regression. Then we used AMOS22.0 software to establish the structural equation model of the relationship between the above three independent variables. Finally, we used bootstrapping method to analyze the direct effect, indirect effect and total effect of independent variables on settlement intention.

Results: The settlement intention of members of the floating population after participating in basic medical insurance for urban employees was $23.2 \%$ higher than that of those who did not participate. The decision as to whether to apply for a personal social security card is related to their settlement intention. The standardized regression coefficients among social insurance and security, social integration, and settlement intention were positive values, and the $Z$ values of the overall effect, indirect effect, and direct effect were all greater than 1.96; the confidence interval of the indirect effect did not include 0 . We found that this model is a partial intermediary model, with an intermediary ratio of $10.66 \%$.
\end{abstract}

Conclusions: This article highlights the important impact of basic medical insurance for urban employees and individual social security cards on the floating population. The conclusions of this study provide suggestions for the government to use when designing policies to enhance the settlement intentions of the floating population and to improve the development of public health undertakings.

Keywords: Medical insurance, Urban employee basic medical insurance, Social security card, Floating population, Settlement intention, Public health

\footnotetext{
*Correspondence: doudongmei1224@126.com

${ }^{\dagger}$ Yulin Li and Lingling Huang contributed equally to this work

${ }^{1}$ School of Nursing and Health, Institute for Chronic Disease Risk Assessment, Henan University, Kaifeng 475004, China

Full list of author information is available at the end of the article
}

\section{Introduction}

With the acceleration of economic development and urbanization, a large floating population has emerged in China. According to the $<$ China Statistic original author(s) and the source, provide a link to the Creative Commons licence, and indicate if changes were made. The images or other third party material in this article are included in the article's Creative Commons licence, unless indicated otherwise in a credit line to the material. If material is not included in the article's Creative Commons licence and your intended use is not permitted by statutory regulation or exceeds the permitted use, you will need to obtain permission directly from the copyright holder. To view a copy of this licence, visit http://creativecommons.org/licenses/by/4.0/. The Creative Commons Public Domain Dedication waiver (http://creativeco mmons.org/publicdomain/zero/1.0/) applies to the data made available in this article, unless otherwise stated in a credit line to the data. 
Almanac > (2019), the floating population was 244 million in 2017 and 241 million in 2018 [1]. The "Statistical Bulletin of National Economic and Social Development 2019" released by the National Bureau of Statistics declared that there was a floating population of 236 million in 2019 [2]. Based on the current situation, the floating population in the future will maintain this considerable size [3]. The floating population is defined as individuals whose registered permanent residence is their original residence, and they live and work in a current residence that is not their registered permanent residence [4-6]. Settlement intention is defined as the thoughts of the floating population about their future relocation arrangements after they have been in their current residence for some time. Medical insurance is a social insurance system established to compensate workers for economic losses caused by disease risks, which comprises three schemes: Basic Medical Insurance for Urban Employees (BMIUE), the Rural New Cooperative Medical Scheme (RNCMS) and Basic Medical Insurance for Urban Residents (BMIUR) [7-9]. BMIUE was the medical insurance introduced in China in 1988. It is jointly paid by the unit and the employee; RNCMS was a form of community-based health insurance, was established and offered cover to rural residents in 2003. Its premiums are mainly subsidized by the local government; BMIUR, a local government-subsidized medical insurance scheme for the unemployed in urban areas, was launched on a pilot basis in 2007. In 2016, RNCMS and BMIUR were merged into medical insurance for urban and rural residents [10]. In this article, medical insurance refers to BMIUE. Social security cards are electronic certificates that provide labor security for workers who work in the fields. All people who participate in social insurance can apply for a social security card. The main items of social insurance include endowment insurance, medical insurance, unemployment insurance, work-related injury insurance and maternity insurance.

Researchers have shown that the individual characteristics of the floating population and the characteristics of the place of origin and current residence can influence the floating population's settlement intention, such as whether to purchase urban housing and housing conditions [11, 12], family migration [13], environment and regional differences $[14,15]$, education level, work status, and social integration [5]. However, little attention has been paid to the impact of medical insurance and social security cards on the floating population's settlement intentions.

The research on the medical security of the floating population is of great significance and value to the field of public health. If the floating population is not sure whether to participate in medical insurance at their current place of residence, this will pose a major challenge to the prevention and treatment of infectious diseases in the field of public health at their current residence $[16,17]$. There is also research evidence that providing medical insurance to the floating population in their current residence will significantly improve the stability of the floating population's life and work [18, 19]. Ultimately, this will improve access to health services and the subjective well-being of the floating population [20]. In terms of BMIUE, BMIUE is jointly paid by units and individuals, which can reduce the economic burden of the floating population and help them settle down in the place where they live.

Social security cards can be used to verify the identity of the patient when they purchase medicine or medical treatment, to store personal account funds and to record the medical treatment of the insured, which will encourage migrants to settle where they live [21]. It can also handle job-seeking registration and unemployment registration procedures; Claiming unemployment insurance benefits; Applying for employment training; Apply for labor ability appraisal and apply for and enjoy treatment of industrial injury insurance; Deal with related labor and social security affairs on the net. It is clear that these elements of social security and medical services are closely related to the social integration of migrants in their places of residence [20,22, 23].

Social integration refers to the process of integrating into a new environment, which is a multidimensional concept [24-27]. It is a hot spot in the fields of public health and social science, and it not only promotes the resettlement intentions of the floating population $[28,29]$ but also has health benefits [30-32].

Research on the willingness of the floating population to settle down will not only promote the development of urbanization [33] but also contribute to the control of infectious diseases and chronic noncommunicable diseases in their place of residence [34]. Finally, it will improve the level of public health services and accelerate social and economic development.

Therefore, the objective of this article is to use the 2017 survey data about the dynamic monitoring of China's floating population (Volume A) to analyze the influence of BMIUE and social security cards on the floating population's settlement intentions. To examine the comprehensive causal relationships, "social integration" was introduced as a mediator variable.

\section{Methods}

Data sources and Variables

The data in this paper are from the existing questionnaire survey in China floating population data platform [35]. The questionnaires were collected from a total of 169,989 
floating population from 31 provinces (autonomous regions and municipalities directly under the Central Government) and Xinjiang Production and Construction Corps. All of them came from the inflow areas where China's floating population is relatively concentrated [36]. After deleting part of the missing data and replacing the mean value, 154,586 people were finally included in the analysis. The proportion is $90.9 \%$.

The core independent variables of this article were BMIUE and social security cards, including the decision whether to participate in BMIUE and whether to apply for a personal social security card. The dependent variable was the settlement intention. This was measured according to whether the individual was willing to move their household registration to their current residence. The mediator variable was social integration. Social integration includes social, economic, cultural and other aspects of integration [37]. It is measured in terms of whether migrants agree to become part of the local population.

The control variables were as follows: (a) demographic characteristics (i.e., age, gender, marital status, the household registration system, and education level), (b) economic characteristics (i.e., average monthly total local expenditure over the past year and whether a labor contract has been signed), (c) flowing characteristics (i.e., flowing range and flowing time), (d) health education (i.e., whether to receive health education on occupational disease prevention, whether to receive health education on STD and AIDS prevention, and whether to receive health education on the prevention and treatment of chronic diseases). Studies have proven that the factors influencing the settlement intentions inflow factors, outflow factors, barriers between the inflow and outflow areas, and the floating population's self-factors [37]. Therefore, these variables were also selected in this study.

\section{Statistical methods \\ Descriptive statistics and logistic regression analysis}

Firstly, we used SPSS 21.0 software to describe the demographic indicators of the floating population, the participation in BMIUE, the application for social security card and the residence intention of the floating population by frequency and percentage. Then the input method was used to analyze the influence of BMIUE, social security card and social integration on settlement intention by binary logistic regression.

\section{Structural Equation Model (SEM)}

We used AMOS22.0 software to analyze the influence path and effect of various factors on settlement intention. Then the goodness of fit of the model was evaluated by Index of Good Fit (GFI), Adjust the Index of Good Fit
(AGFI), Comparative Fit Index (CFI), Root Mean Square Error of Approximation (RMSEA). The criteria for model fitting are GFI $>0.9$, AGFI $>0.9$, CFI $>0.9$, RMSEA $<0.05$ [38-40]. Remember, if the model fitting result is poor, the model needs to be improved in combination with the professional. Finally, we used bootstrapping method [4143] to analyze the direct effect, indirect effect and total effect of independent variables on settlement intention. This method provided direction for interventions [44, 45].

\section{Results \\ Descriptive analysis}

According to Table 1, 39.9\% of the floating population expressed their willingness to move their household registration system to the local area and settle there. This result is similar to the findings of previous research [46]. Of the respondents, approximately $77.7 \%$ did not participate in BMIUE, and $50.5 \%$ of the floating population had applied for a personal social security card. In addition, the survey found that the floating population had good social integration at their current residence (93.7\%).

Regarding demographic characteristics, the majority of the respondents were rural residents, married, and young or middle-aged men (95.2\%), and nearly $43.5 \%$ of the respondents stopped their education in junior high school. In addition, $51.5 \%$ of the floating population was within the province of their registered residence, and their migration time was less than 8 years. Nearly 58\% of them had signed labor contracts, and their average monthly expenditure in the past year on health care was 1000-3000 yuan. In terms of health education, the floating population received the most health education on STD and AIDS prevention, but their overall acceptance of health education was poor.

\section{Binary logistic regression results of BMIUE, social security card, social integration, and settlement intention}

Table 2 shows the results of binary logistic regression, which shows that participation in basic medical insurance for urban employees (BMIUE) has an impact on the resettlement intention of floating population. Specifically, the settlement intention of individuals in the floating population participating in BMIUE was $23.2 \%$ higher than that of those who did not participate. During the single factor analysis, it found that applying for a personal social security card was related to the settlement intention. Moreover, the proportion of floating population agreeing to settle that they were already part of the society was 2.026-fold greater than that of the floating population that did not agree to settle. This demonstrated that social integration has a positive impact on the settlement intentions of the floating population. 
Table 1 Description of the variables included in the analysis $(N=154,586)$

\begin{tabular}{|c|c|c|c|}
\hline Variables & Categories & Frequency & Percentage (\%) \\
\hline \multicolumn{4}{|l|}{ Demographic characteristics } \\
\hline \multirow[t]{3}{*}{ Age } & $18-35=0$ & 63,089 & 40.80 \\
\hline & $35-60=1$ & 84,032 & 54.40 \\
\hline & $\geq 60=2$ & 7465 & 4.80 \\
\hline \multirow[t]{2}{*}{ Gender } & Male $=0$ & 79,577 & 51.50 \\
\hline & Female $=1$ & 75,009 & 48.50 \\
\hline \multirow[t]{3}{*}{ Marital status } & Unmarried $=0$ & 21,063 & 13.60 \\
\hline & Married $=1$ & 128,038 & 82.80 \\
\hline & Divorce and others $=2$ & 5485 & 3.50 \\
\hline \multirow[t]{3}{*}{ The household registration system } & Agriculture $=0$ & 119,675 & 77.40 \\
\hline & Non-agricultural $=1$ & 22,858 & 14.80 \\
\hline & Other $=2$ & 12,053 & 7.80 \\
\hline \multirow[t]{4}{*}{ Education } & Elementary school and below $=0$ & 26,358 & 17.10 \\
\hline & Junior high school = 1 & 67,181 & 43.50 \\
\hline & High school, technical secondary school $=2$ & 33,785 & 21.90 \\
\hline & College and above $=3$ & 27,262 & 17.60 \\
\hline \multicolumn{4}{|l|}{ Economic characteristics } \\
\hline \multirow[t]{4}{*}{ Average monthly total local expenditure (yuan) } & $<1000=0$ & 10,645 & 6.90 \\
\hline & $1000-3000=1$ & 76,673 & 49.60 \\
\hline & $3000-5000=2$ & 44,498 & 28.80 \\
\hline & $>5000=3$ & 22,770 & 14.70 \\
\hline \multirow[t]{2}{*}{ Labor contracts } & Sign a contract $=0$ & 89,323 & 57.80 \\
\hline & No contract signed $=1$ & 65,263 & 42.20 \\
\hline \multicolumn{4}{|l|}{ Flowing characteristics } \\
\hline \multirow[t]{3}{*}{ Flowing range } & Interprovincial = 1 & 74,875 & 48.40 \\
\hline & Intercity $=2$ & 51,682 & 33.40 \\
\hline & Cross County $=3$ & 28,029 & 18.10 \\
\hline \multirow[t]{4}{*}{ Flowing time (years) } & $<8=0$ & 81,793 & 52.90 \\
\hline & $8-14=1$ & 43,688 & 28.30 \\
\hline & $14-20=2$ & 18,356 & 11.90 \\
\hline & $>20=3$ & 10,749 & 7.00 \\
\hline \multicolumn{4}{|l|}{ Health education } \\
\hline \multirow[t]{2}{*}{ Health education in occupational disease prevention } & $\mathrm{No}=0$ & 103,008 & 66.60 \\
\hline & Yes $=1$ & 51,578 & 33.40 \\
\hline \multirow[t]{2}{*}{ Health education on STD and AIDS prevention } & $\mathrm{No}=0$ & 93,286 & 60.30 \\
\hline & Yes $=1$ & 61,300 & 39.70 \\
\hline \multirow[t]{2}{*}{ Health education on prevention and treatment of chronic diseases } & $\mathrm{No}=0$ & 96,713 & 62.60 \\
\hline & Yes $=1$ & 57,873 & 37.40 \\
\hline \multicolumn{4}{|l|}{ Insurance and Social security card } \\
\hline \multirow[t]{2}{*}{ Urban employee basic medical insurance } & $\mathrm{No}=0$ & 120,176 & 77.70 \\
\hline & Yes $=1$ & 34,410 & 22.30 \\
\hline \multirow[t]{2}{*}{ Apply for a personal social security card } & Did not apply $=0$ & 76,535 & 49.50 \\
\hline & Apply $=1$ & 78,051 & 50.50 \\
\hline \multirow[t]{2}{*}{ Do you agree that I think locals are willing to accept me as a member? } & Disagree $=0$ & 10,380 & 6.70 \\
\hline & Agree $=1$ & 144,206 & 93.70 \\
\hline \multirow{2}{*}{$\begin{array}{l}\text { Do you agree with move your household registration to the current } \\
\text { residence? }\end{array}$} & Disagree $=0$ & 92,931 & 60.10 \\
\hline & Agree $=1$ & 61,655 & 39.90 \\
\hline
\end{tabular}


Table 2 Logistic analysis of influencing factors of settlement intention

\begin{tabular}{|c|c|c|c|c|c|c|c|c|}
\hline & \multirow[t]{2}{*}{ B } & \multirow[t]{2}{*}{ S.E } & \multirow[t]{2}{*}{ Wals } & \multirow[t]{2}{*}{ df } & \multirow[t]{2}{*}{ Sig } & \multirow[t]{2}{*}{$\operatorname{Exp}(B)$} & \multicolumn{2}{|c|}{$\operatorname{EXP}(B) 95 \% \mathrm{Cl}$} \\
\hline & & & & & & & Lower limit & Upper limit \\
\hline Age & -.016 & .018 & .776 & 1 & .378 & .985 & .951 & 1.019 \\
\hline Gender & .105 & .016 & 43.189 & 1 & .000 & 1.110 & 1.076 & 1.145 \\
\hline Marital status & .088 & .019 & 21.178 & 1 & .000 & 1.092 & 1.052 & 1.134 \\
\hline Education & .250 & .010 & 642.384 & 1 & .000 & 1.285 & 1.260 & 1.310 \\
\hline The household registration system & .249 & .013 & 362.815 & 1 & .000 & 1.283 & 1.251 & 1.316 \\
\hline Average monthly total local expenditure & .174 & .010 & 278.571 & 1 & .000 & 1.190 & 1.166 & 1.215 \\
\hline Labor contracts & -.056 & .019 & 8.408 & 1 & .004 & .945 & .910 & .982 \\
\hline Flowing range & -.304 & .011 & 772.995 & 1 & .000 & .738 & .723 & .754 \\
\hline Flowing time & .167 & .010 & 306.207 & 1 & .000 & 1.182 & 1.160 & 1.204 \\
\hline Basic medical insurance for urban employees (BMIUE) & .209 & .021 & 97.274 & 1 & .000 & 1.232 & 1.182 & 1.284 \\
\hline Apply for a personal social security card & .020 & .019 & 1.090 & 1 & .297 & 1.020 & .983 & 1.059 \\
\hline Health education in occupational disease prevention Health education & -.151 & .022 & 47.978 & 1 & .000 & .859 & .823 & .897 \\
\hline on prevention and treatment of chronic diseases & .121 & .023 & 29.038 & 1 & .000 & 1.129 & 1.080 & 1.180 \\
\hline Health education on STD and AIDS prevention & .016 & .023 & .530 & 1 & .467 & 1.017 & .973 & 1.062 \\
\hline Do you agree that I think locals are willing to accept me as a member? & .706 & .033 & 456.131 & 1 & .000 & 2.026 & 1.899 & 2.161 \\
\hline Constant & -1.823 & .053 & 1168.340 & 1 & .000 & .162 & & \\
\hline
\end{tabular}

\section{Structural Equation Model and the mediating effect of social integration}

The structural equation model is shown in Fig. 1. SEM is composed of three latent variables: social insurance and security, social integration and settlement intention. Figure 1 shows that the standardized regression coefficients among social insurance and security, social integration, and settlement intention are positive values, which means social insurance and security and social integration have a positive impact on the resettlement intention of floating population. According to the model results, the factor loading coefficient of each observed variable is greater than 0.5. And the values in Table 3 are positive, which indicates that each variable is statistically significant.

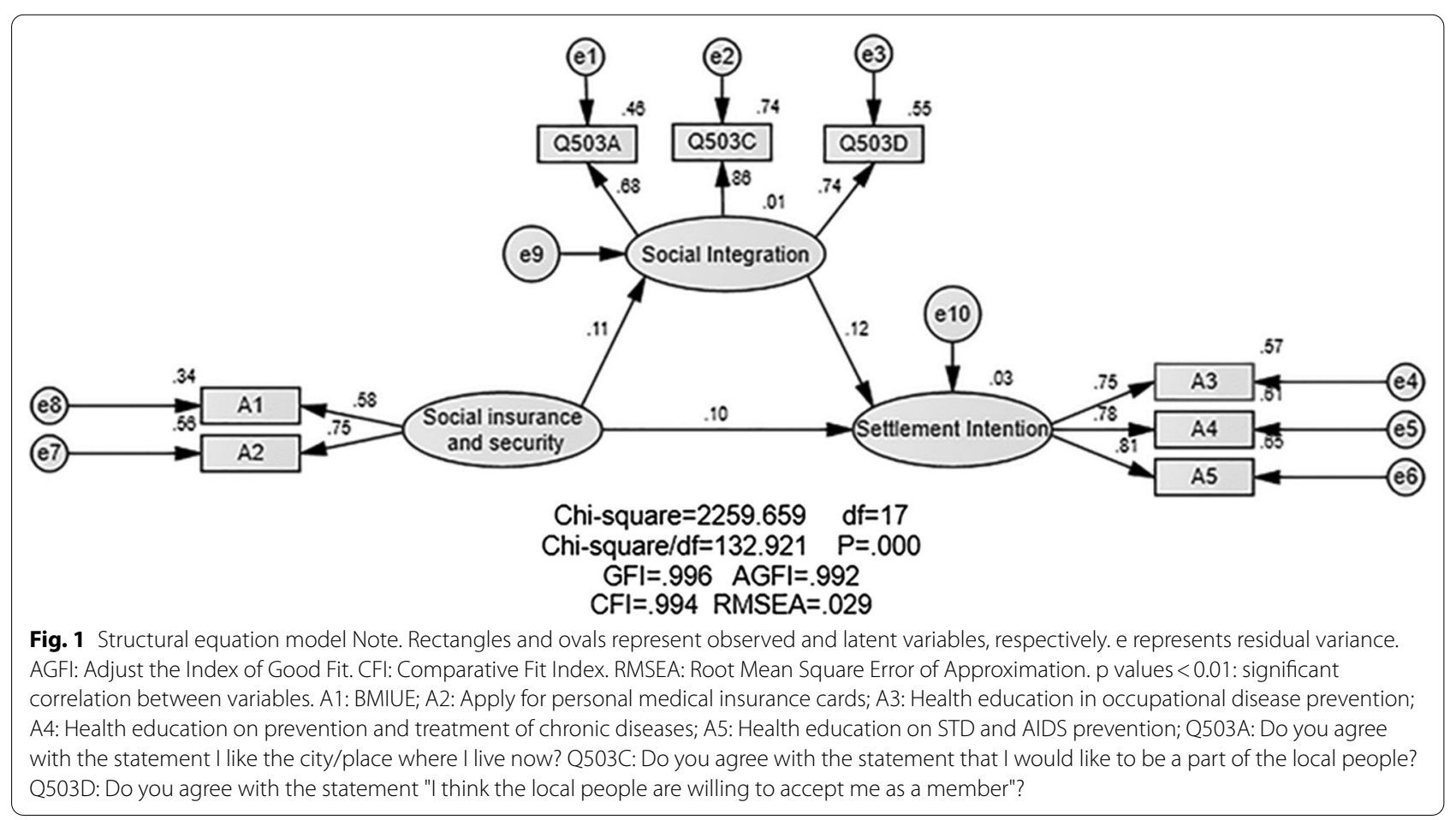


Table 3 Regression weights

\begin{tabular}{|c|c|c|c|c|c|c|c|}
\hline & & & Estimate & S.E & C.R & $P$ & Label \\
\hline Social integration & $<---$ & Social Security & .115 & .004 & 26.216 & $* * *$ & \\
\hline Settlement intention & $<--$ & Social Security & .099 & .004 & 25.070 & $* * *$ & \\
\hline Settlement intention & $<--$ & Social integration & .109 & .003 & 38.361 & $* * *$ & \\
\hline A3 & $<---$ & Settlement intention & 1.000 & & & & \\
\hline A4 & $<---$ & Settlement intention & 1.063 & .004 & 268.101 & $* * *$ & \\
\hline A5 & $<--$ & Settlement intention & 1.111 & .004 & 269.905 & $* * *$ & \\
\hline A2 & $<--$ & Social Security & 1.000 & & & & \\
\hline A1 & $<---$ & Social Security & .642 & .019 & 33.247 & $* * *$ & \\
\hline Q503A & $<--$ & Social integration & 1.000 & & & & \\
\hline Q503C & $<--$ & Social integration & 1.387 & .006 & 239.244 & $* * *$ & \\
\hline Q503D & $<---$ & Social integration & 1.181 & .005 & 241.402 & $* * *$ & \\
\hline
\end{tabular}

A1: BMIUE; A2: Apply for personal medical insurance cards; A3: Health education in occupational disease prevention; A4: Health education on prevention and treatment of chronic diseases; A5: Health education on STD and AIDS prevention; Q503A: Do you agree with the statement I like the city/place where I live now? Q503C: Do you agree with the statement that I would like to be a part of the local people? Q503D: Do you agree with the statement "I think the local people are willing to accept me as a member"? ${ }^{* * *} p<0.01$

Table 4 Evaluation Index of Model Fit

\begin{tabular}{llc}
\hline Absolute fit index & Fit standard & Fitness index \\
\hline $\mathrm{NC}(\mathrm{X} 2 / \mathrm{df})$ & $1<\mathrm{NC}<3$ & 132.92 \\
$P$ & The smaller the better & 0.00 \\
$\mathrm{GFI}$ & $>0.9$ Good fit & 1.00 \\
$\mathrm{AGFI}$ & $>0.9$ Good fit & 0.99 \\
$\mathrm{CFI}$ & $>0.9$ Good fit & 0.99 \\
RMSEA & $<0.05$ Good fit & 0.03 \\
\hline
\end{tabular}

GFI: goodness-of-fit index. AGFI: adjusted goodness-of-fit index. CFI: comparative fitness index. RMSEA: root mean square error of approximation

Table 4 shows the goodness-of-fit indices. The fitness indexes (GFI/AGFI/CFI) were all greater than 0.9, and the RMSEA was less than 0.05 . This shows that the model has a good fitting effect.

Mediation analysis is an important tool for statisticians to study causality. The intention is to study whether or to what extent the independent variable acts on the dependent variable via the mediator variable and to clarify the direct effect, indirect effect, and total effect [41, 42]. To further clarify the causal relationship, the study analyzed the intermediary effect by using the bootstrapping method. The reliability of the direct effect, indirect effect, and total effect was $0.600,0.804$, and 0.823 , and the validity was $0.500,0.695$, and 0.719 , respectively. The results of the mediation effect using the bootstrapping method are presented in Table 5. It was found that the $\mathrm{Z}$ values of the overall effect, indirect effect, and direct effect were all greater than 1.96, and the confidence interval of the indirect effect does not include 0 , indicating that both direct and indirect effects exist in this model. This model is a partial intermediary, with an intermediary ratio of $10.66 \%$.

\section{Discussion}

After binary logistic regression analysis and structural equation model mediation effect analysis, it was concluded that BMIUE, personal social security card application and social integration not only directly promote the settlement intentions of the floating population but

Table 5 Direct and indirect effects of social insurance and security cards on settlement intention

\begin{tabular}{|c|c|c|c|c|c|c|c|}
\hline \multirow[t]{3}{*}{ Variables } & \multirow[t]{3}{*}{ Estimate } & \multirow[t]{3}{*}{ S.E } & \multirow[t]{3}{*}{$\mathbf{Z}$} & \multicolumn{4}{|c|}{ Bootstrapping } \\
\hline & & & & \multicolumn{2}{|c|}{ Bias-corrected $95 \% \mathrm{Cl}$} & \multicolumn{2}{|c|}{ Percentile $95 \% \mathrm{Cl}$} \\
\hline & & & & Lower & Upper & Lower & Upper \\
\hline \multicolumn{8}{|l|}{ Total effect } \\
\hline Insurance and security-Settlement intention & 0.122 & 0.004 & 30.500 & 0.105 & 0.118 & 0.105 & 0.118 \\
\hline \multicolumn{8}{|l|}{ Indirect effect } \\
\hline Insurance and security-Settlement intention & 0.013 & 0.001 & 13.000 & 0.011 & 0.014 & 0.011 & 0.014 \\
\hline \multicolumn{8}{|l|}{ Direct effect } \\
\hline Insurance and security-Settlement intention & 0.109 & 0.003 & 36.333 & 0.104 & 0.115 & 0.104 & 0.115 \\
\hline
\end{tabular}


also promote the settlement of the floating population in their current residence through the intermediary variable of social integration.

\section{BMIUE, social security cards, and settlement intentions}

Participating in BMIUE in the current residence is very important for the future settlement intentions of the floating population. Participation in BMIUE has a positive impact on the settlement intentions of the floating population, and the impact on the settlement intention is greater than that of participating in other types of insurance [47], which is consistent with the findings of previous studies $[48,49]$. In addition, researchers previously found that the participation of the floating population in BMIUE in big cities would contribute to their intentions to settle down [50]. More importantly, participating in BMIUE can improve the risk resistance of the floating population at their current residence, reduce their cost of living and reduce their economic burden to a certain extent [51-53]. BMIUE is paid for by both the employer and the employee [54], and the employer pays more than each individual. Employees only need to pay for a certain number of years to enjoy higher rates of medical insurance reimbursement for life. Therefore, this will enhance the floating population's intention to settle down to some extent. Even without considering the preferences of migrant workers, the participation in medical insurance still has a positive impact on the willingness of the floating population to settle down [55-57].

In 2009, the state promulgated the Interim Measures on the Continuity of the Basic Medical Security for Floating Employed Persons, which clearly stipulates that local governments should not set up barriers to the participation of the floating population for reasons such as having registered permanent residence. If rural household registration personnel are employed in urban units and have stable labor relations, the employing units shall go through registration procedures in accordance with the provisions of the Interim Measures for the Administration of Social Insurance Registration and participate in the basic medical insurance for urban workers in the place of employment. Other mobile employment, can voluntarily choose to participate in the new rural cooperative medical care in the place of household registration or the urban basic medical insurance in the place of employment, and according to the relevant provisions to the new rural cooperative medical care agency in the place of household registration or the social (medical) insurance agency in the place of employment for registration procedures; Urban basic medical insurance ginseng protect personnel to cross flow as a whole the area of employment, without receiving unit, the individual should be suspended within 3 months after the original relationship of insurance of primary medical treatment to the new employment to social (medical) insurance agency organization is dealt with register formalities, participate in BMIUE in accordance with local regulations or BMIUR [58]. However, according to the survey results of this paper, there are still some people who do not participate in BMIUE.

The reason that produces this kind of result may be floating population attends insurance in place of origin, the insurance after transforming the job is interrupted, cannot timely pay is sure; The floating population is not stable in their current residence, even in the informal sector of employment; Reimbursement procedures are complicated and the reimbursement ratio is lower than that of the place of origin. In violation of the Labor Contract Law, some units do not sign labor contracts with the floating population and refuse to pay insurance premiums [59]; The provinces where the floating population flows into have weak economic strength and insufficient medical insurance funds [60].

Social security cards had a positive effect on the settlement intentions of the floating population, which is consistent with previous studies $[61,62]$. It has been documented that the issuance of and application for a social security card is an important push to relieve the worries of the floating population and promote the construction of new urban areas. The social security card is an important guarantee for the floating population that encourages them to integrate into their current residence and live a stable life [63]. Migrants can receive a social security card as long as they are insured in their place of residence. These cards are used for the identification of their medical insurance, and they are also used to record the basic information of the insured persons, payment status, treatments, payment of medical funds and other information [64]. In addition, it can also handle job-seeking registration and unemployment registration procedures;

Claiming unemployment insurance benefits; Applying for employment training; Apply for labor ability appraisal and apply for and enjoy treatment of industrial injury insurance; Deal with related labor and social security affairs on the net. Therefore, even though it had an effect on the settlement intention in the single-factor analysis and no effect on the regression analysis, this study still included the social security card in the final model. But we have to note that half of them still don't have a social security card. The reasons may be: The time limit of insurance payment is less than 3 months [65]; Change your name, photo and service bank before you can apply for again [66]; Failing to renew your social security card before it expires [67]. 


\section{Social integration and settlement intention}

Social integration has become an important factor affecting the settlement intentions of the floating population [68]. With the development of urbanization, the floating population has paid increasing attention to their acceptance in the local society [50]. The "people-centered" urbanization policy put forward by the Chinese government in 2014 shows that urbanization is the urbanization of people, and the degree of social integration is closely related to the degree of the acceptance of the floating population by the local people [69-71]. This is consistent with the selection of the social integration measurement criteria in this paper because the current residence provides abundant social resources and conditions for the floating population, which will help them integrate into the local life as soon as possible [72]. The longer the influx takes, the stronger the positive effect of social integration on settlement intentions [73].

\section{The mediating effect of social integration}

Participation in BMIUE in the place of residence is an important indicator to measure social integration [74]. Participation in BMIUE will promote the social integration of the floating population in the local area [75], which is consistent with the results of this study. This may be because the eligibility for BMIUE indicates that the floating population has a fixed source of income and a stable work unit in their current place of residence, and their living conditions are relatively good, which can meet the basic living needs of the floating population. Participating in social insurance is the only requirement for obtaining a social security card. Therefore, BMIUE and social security cards, which are closely related to social security, are important factors affecting the social integration of the floating population. They will increase the sense of belonging of the floating population in their current place of residence and ultimately improve their willingness to settle down [76].

\section{Settlement intention and public health}

An increase in permanent residence will not only improve the health management level of the floating population in their place of residence but also promote the improvement of public health. The residents' health records are an important part of the twelve contents of the national basic public health service, which takes personal health as the core and satisfies the residents' self-care and health management [77]. Studies have shown that long-term settlement intention can significantly promote the service utilization of the health records of the floating population [78], which is beneficial to the physical health of the floating population. At the same time, settlement intention will also improve the level of public services [79-81]. As their willingness to stay increases, so does the prevention of communicable and noncommunicable diseases in the place of residence. This is because the willingness to stay promotes urbanization, which leads to an increase in global risk factors for infectious and noncommunicable diseases [82-84]. Specifically, China's public health service system for the floating population is not sound, and there is a lack of disease data from the floating population on infectious diseases and chronic noncommunicable diseases, making it difficult to establish a disease surveillance system [84-86]. This leads to the absence of prevention and the control of disease in vulnerable groups such as the floating population in China, and makes infectious diseases such as tuberculosis an important threat to public health $[84,85]$. For example, in the COVID-19 epidemic in 2019, the floating population will be at increased risk of COVID-19 infection due to their high rates of chronic disease comorbidities [87-89]. Additionally, because of their different medical insurance coverage, some vulnerable groups will not be able to timely treatment $[84,88]$. As a result, some countries, including China, have taken measures to control migration flows to control the COVID-19 epidemic [23].

To sum up, BMIUE and social security cards, as part of social security, have a direct positive impact on the floating population. Social integration, which is closely related to social security and public services, also has a direct positive impact on the resettlement intentions of the floating population. This study proved the mediating effect of social integration through constructing a model; BMIUE and social security cards can promote the settlement intentions of the floating population through social integration. The increase in permanent residence will eventually improve the health management level of the floating population and promote the development of public health.

However, this study also has some limitations. The results of this study are based on mining of existing data. Due to the limited variables in the original data, the reliability of some indicators and the intermediary ratio is low. If one can add new effective variables in the future, the explanation of the influence of medical insurance and social security cards on the settlement intentions of the floating population will be more complete.

\section{Conclusions}

In this paper, the dynamic monitoring data of China's floating population in 2017 were used to study the influence of BMIUE and social security cards on the settlement intentions of the floating population, taking 
social integration as a mediating variable. According to the mediating effect method of the structural equation model, BMIUE and social security cards not only have a direct positive impact on the floating population but also indirectly affect their settlement intentions through social integration. Therefore, the government should further improve the insurance policies of the floating population in their current place of residence, encourage the floating population to integrate into society, and further enhance their intention to settle down. At the same time, settlement intention will also promote the development of public health and economic development. Although the data used in this paper were obtained from developing countries, this result also provides a theoretical basis for improving population migration policies internationally.

\section{Abbreviations}

BMIUE: Basic medical insurance for urban employees; BMIUR: Basic Medical Insurance for Urban Residents; RNCMS: Rural New Cooperative Medical Scheme; GFI: Index of Good Fit; AGFI: Adjust the Index of Good Fit; CFI: Comparative Fit Index; RMSEA: Root Mean Square Error of Approximation; SEM: Structural Equation Model.

\section{Acknowledgements}

The author would like to thank all the professors and senior teachers: DMD conducted the data analyses. LLH help the author drafted the manuscript. DMD, LX, and LLH finalized the manuscript with inputs from all authors.

\section{Authors' contributions}

DMD conducted the data analyses. YLL and LLH drafted the manuscript. DMD, LX,YLL and LLH finalized the manuscript with inputs from all authors. All authors contributed to the development of the study framework, interpretation of the results, revisions of successive drafts of the manuscript. All authors read and approved the final manuscript.

\section{Funding}

Not applicable.

\section{Availability of data and materials}

The datasets generated and analysed during the current study are available in the Migrant Population Service Center, National Health Commission P.R. China repository, http://www.chinaldrk.org.cn/wjw/\#/data/classify/population/yearL ist.

\section{Declarations}

\section{Ethics approval and consent to participate}

The study protocol was approved by Ethics Committee of Biomedical Research, Henan University. The committee's reference number: HUSOM2020-267.

\section{Consent for publication}

The data used in this article is public.

\section{Competing interests}

The authors declare that they have no competing interests.

\section{Author details}

${ }^{1}$ School of Nursing and Health, Institute for Chronic Disease Risk Assessment, Henan University, Kaifeng 475004, China. ${ }^{2}$ School of Nursing and Health, Lida University, Shanghai 201609, China. ${ }^{3}$ School of Medicine and Health
Management, Tongji Medical College of Huazhong University of Science and Technology, Wuhan 430000, China.

Received: 27 November 2020 Accepted: 23 September 2021

Published online: 09 October 2021

\section{References}

1. Statistics NBo. China Statistic Almanac (2019): China Statistics Press; 2019 updated 2019. http://www.stats.gov.cn/tjsj/ndsj/2019/indexch.htm.

2. Statistics NBo. Statistical Communique of the People's Republic of China on the 2019 National Economic and Social Development: National Bureau of Statistics; 2020 updated 2020: http://www.stats.gov.cn/tjsj/ zxfb/202002/t20200228_1728913.html.

3. Mohabir N, Jiang Y, Ma R. Chinese floating migrants: rural-urban migrant labourers' intentions to stay or return. Habitat Int. 2017;60:101-10.

4. Chen S, Zhao J, Han Z, editors. Study on the influence of floating population on urban economic growth. International Conference on Education \& Management; 2018

5. Cheng Y. The role of willingness in social integration process: a study of floating population in Chinese Cities. Social Sciences. 2013. http://lup.lub. lu.se/student-papers/record/3812485.

6. Sheng M, Gu C, Wu W. To move or to stay in a migrant enclave in Beijing: the role of neighborhood social bonds. J Urban Aff. 2017;41(1):1-16.

7. Huang Z, Pan Z. Improving migrants'access to the public health insurance system in China: a conceptual classification framework. Asian Pac Migr J. 2017;26(2):274-84.

8. Meng Q, Fang H, Liu X, Yuan B, Xu J. Consolidating the social health insurance schemes in China: towards an equitable and efficient health system. The Lancet. 2015;386(10002):1484-92.

9. Yip WC-M, Hsiao WC, Chen W, Hu S, Ma J, Maynard A. Early appraisal of China's huge and complex health-care reforms. The Lancet. 2012;379(9818):833-42.

10. Qingyue $M$, Shenglan T. Universal health care coverage in China: challenges and opportunities. Procedia Soc Behav Sci. 2013;77:330-40.

11. Xie S, Chen J. Beyond homeownership: housing conditions, housing support and rural migrant urban settlement intentions in China. Cities. 2018;78:76-86.

12. Yang S, Guo F. Breaking the barriers: how urban housing ownership has changed migrants€ settlement intentions in China. Urban Studies. 2018;55(16):3689-707.

13. Fan CC, Li T. Split households, family migration and urban settlement: findings from China's 2015 National Floating Population Survey. Soc Incl. 2020;8(1):252-63.

14. Liu Y, Deng W, Song X. Influence factor analysis of migrants' settlement intention: considering the characteristic of city. Appl Geogr. 2018;96:130-40.

15. Paparusso A, Ambrosetti E. To stay or to return? Return migration intentions of Moroccans in Italy. Int Migr. 2017;55(6):137-55.

16. Fan C, Cai T, Gai Z, Wu Y. The relationship between the migrant population's migration network and the risk of COVID-19 transmission in China-empirical analysis and prediction in prefecture-level cities. Int J Environ Res Public Health. 2020;17(8):2630.

17. Chen S, Yang J, Yang W, Wang C, Bärnighausen T. COVID-19 control in China during mass population movements at New Year. The Lancet. 2020;395(10226):764-6.

18. Zheng J, Zhu C. Shanghaishi wailai renkou changqi juzhu yiyuan de shizheng yanjiu[Empirical Study on the long-term residence Intention of migrants in Shanghai]. Shanghai Econ Res. 2014;000(7):122-9.

19. Wang G, Hu J. Social Security and citizenization intention of Urban Migrant Workers. Popul J. 2015;37(06):45-55.

20. Fang Z, Sakellariou C. Social insurance, income and subjective well-being of rural migrants in China-an application of unconditional quantile regression. J Happiness Stud. 2016;17(4):1635-57.

21. Quansheng P. Study on the influence of public service supply on the urban settled willingness of agricultural transfer population-taking Guangzhou as an example: Central China Normal University. 
22. Dalgard OS, Thapa SB. Immigration, social integration and mental health in Norway, with focus on gender differences. Clin Pract Epidemiol Ment Health. 2007;3(1):24.

23. Fothergill KE, Ensminger ME, Robertson J, Green KM, Thorpe RJ, Juon $\mathrm{H}$-S. Effects of social integration on health: a prospective study of community engagement among African American women. Soc Sci Med. 2011;72(2):291-8.

24. Miglietta A, Tartaglia S. The influence of length of stay, linguistic competence, and media exposure in immigrants'adaptation. Cross-Cult Res. 2009;43(1):46-61.

25. Hao Z. Measurement and theoretical perspectives of immigrant assimilation in China. China Popul Today. 2012;06:44

26. LeedahI SN, Chapin RK, Little TD. Multilevel examination of facility characteristics, social integration, and health for older adults living in nursing homes. J Gerontol B Psychol Sci Soc Sci. 2015;70(1):111-22

27. Li S, Delva J. Social capital and smoking among Asian American men: an exploratory study. Am J Public Health. 2012;102(S2):S212-21.

28. Raymond-Flesch M, Auerswald C, Mcglone L, Comfort M, Minnis A. Building social capital to promote adolescent wellbeing: a qualitative study with teens in a Latino agricultural community. BMC Public Health. 2017;17(1):1.

29. Vyncke V, De Clercq B, Stevens V, Costongs C, Barbareschi G, Jónsson SH, et al. Does neighbourhood social capital aid in levelling the social gradient in the health and well-being of children and adolescents? A literature review. BMC Public Health. 2013;13(1):65

30. Jen MH, Sund ER, Johnston R, Jones K. Trustful societies, trustful individuals, and health: an analysis of self-rated health and social trust using the World Value Survey. Health Place. 2010;16(5):1022-9.

31. Kawachi I. Trust and population health. The Oxford handbook of social and political trust. 2018:447-70.

32. Rostila M. Social capital and health in European welfare regimes: a multilevel approach. J Eur Soc Policy. 2007;17(3):223-39.

33. Yang $Q$, Wang $Y$, Li X. The settlement intention and re-migration decision of floating population. Chin. J. Soil Sci. 2019-09-25.

34. Organization WH. Chronic diseases and their common risk factors [Fact sheet]. 2005.

35. The survey data of China's floating population dynamic monitoring 2018. http://www.chinaldrk.org.cn/wjw/\#/data/classify/population/yearList.

36. Dpff P. China's floating population dynamic monitoring survey data in 2017 (Volume A): Data platform for floating Population. 2018. Available from: https://chinaldrk.org.cn/wjw/\#/data/classify/population/yearList.

37. Lin Y, Zhang Q, Chen W, Shi J, Han S, Song X, et al. Association between social integration and health among internal migrants in ZhongShan, China. PloS ONE. 2016;11(2):e0148397.

38. Bentler PM. Comparative fit indexes in structural models. Psychol Bull. 1990;107(2):238

39. Korner M, Wirtz MA, Bengel J, Goritz AS. Relationship of organizational culture, teamwork and job satisfaction in interprofessional teams. BMC Health Serv Res. 2015;15:243.

40. Tsaprantzi AV, Kostagiolas P, Platis C, Aggelidis VP, Niakas D. The Impact of Information on Doctors' Attitudes Toward Generic Drugs. Inquiry. 2016:53.

41. Hayes A. Introduction to mediation, moderation, and conditional process analysis. J Educ Meas. 2013;51(3):335-7.

42. Preacher KJ, Kelley K. Effect size measures for mediation models: quantitative strategies for communicating indirect effects. Psychol Methods. 2011;16(2):93-115.

43. Mackinnon DP. Introduction to statistical mediation analysis. New York: McGraw-Hill; 2008.

44. Hayes AF. Beyond Baron and Kenny: statistical mediation analysis in the new millennium. Commun Monogr. 2009;76(4):408-20.

45. Mackinnon DP. Integrating mediators and moderators in research design. Res Soc Work Pract. 2011;21(6):675-81.

46. Qiu H, Zhou W. Analysis on settlement intention and influencing factors of floating population. J Population. 2019;41(05):91-100.

47. Zhu M, Shi X. A Study on the Long-term residence Intention of migrant workers from the perspective of medical insurance. Future Dev. 2017:41(02):54-8.

48. You Z, Yang H, Fu M. Settlement intention characteristics and determinants in floating populations in Chinese border cities. Sustain Cities Soc 2018:39:476-86.
49. Tang SS, Feng JX. Cohort differences in the urban settlement intentions of rural migrants: a case study in Jiangsu Province, China. Habitat Int. 2015:49:357-65.

50. Lin L, Zhu Y, Ke W, Wang J. The effect of basic public services on the residence willingness of floating population in different cities. J Geogr. 2019;74(04):737-52.

51. Shi Z, Shi N. Nongmingong de shehui baozhang yu chengshi rongru fenxi. Popul Dev. 2014;20(2):33-43.

52. Wang $S, X u S$. Liuru renkou shehui rongrugan de jiegou yu yingxiang yinsu fenxi-jiyu jilinsheng de diaocha shuju. Popul J. 2013;01:5-14.

53. Wang Z. Nongmingong chengshi shehui rongru de cedu ji yingxiang yinsu-jian yuchengzhen liudong renkou de bijiao. Res Labor Econ. 2015:2:41-61.

54. Yao Q, Liu C, Sun J. Inequality in health services for internal migrants in china: A national cross-sectional study on the role of fund location of social health insurance. Int J Environ Res Public Health. 2020;17(17):6327.

55. Qin L, Chen CP, Liu X, Wang C, Jiang Z. Health status and earnings of migrant workers from rural China. China World Econ. 2015;23(2):84-99.

56. Tang S, Feng J. Cohort differences in the urban settlement intentions of rural migrants: a case study in Jiangsu Province, China. Habitat Int. 2015;49:357-65.

57. Chen F, Tao S, Zhang J. Current situation of medical insurance of floating population and its influence on long-term residence intention-based on dynamic monitoring data of floating population in Beijing, Tianjin and Hebei. Res World. 2017:11:37-42.

58. Security MoHRaS. Interim measures for transfer and continuation of basic medical security for floating employed persons 2009. http://www. mohrss.gov.cn/gkml/zlbmxgwj/ylbx_3063/201407/t20140717_136139. html.

59. Zhang Y, Song L. Influencing factors of medical insurance participation rate of floating population in Beijing-Tianjin-Hebei Region. Hebei Agric Mach. 2020;10:119-21.

60. Liu Z, Wang H. Influential factors on the rate of medical insurance participation of migrant population: an analysis based on china national monitoring data of migrant population. J Zhejiang Univ. 2014;44:5.

61. Li H, Xie Y. Liudong renkou shinian yanjiu: redian, qushi, ji qianyan. Popul Soc. 2018;034(4):51-63.

62. Yang J, Pan Z. Research on the Structure, Current Situation, and Influence Factors of the Social Inclusion of Migrant Workers: Based on "Three Inclusions" of Migrant Workers Survey in Hunan Province. 2015 IEEE International Conference on Smart City/SocialCom/SustainCom (SmartCity)2015. p. 524-7.

63. Liu G. We will steadily promote the issuance and application of social security CARDS and effectively provide convenient and efficient social security services to the public. 2013-05-04.

64. Letter in response to proposal No. 2351 (Medical sports Class no. 237) of the second session of the 13th National Committee of the CPPCC 2020 [Available from: http://www.nhc.gov.cn/wjw/tia/202009/e6c9f76aa9 ec4f7db3152ac13cdf4bc4.shtml

65. https://www.findlaw.cn/142000/article_93507.html.

66. Government OotSMPs. Procedures of Shanghai Municipality for the administration of social security cards. Bull Shanghai Munic People's Gov. 2019;21:3-6.

67. Feng Q. Read through "Social Security Card."Tianjin Soc Insurance. 2010;06:39-40

68. Zhang X, Zhou S, Yao J. Residence decision, settlement intention and social integration: An empirical study based on urban and rural floating population. Humanit Mag. 2018;04:39-48.

69. TCCCatS C. National New Urbanization Plan (2014-2020): The CPC Central Committee and the State Council. 2014. Available from: http://www.gov. cn/gongbao/content/2014/content_2644805.htm.

70. Zhang $\mathrm{H}, \mathrm{Cao} Y$, Wang $M$. The influence of social integration on the long-term residence intention of floating population in Guangzhou. Northwest population. 2015;36(1):7-11.

71. Agency TXN. National New Urbanization Plan (2014-2020) 2014 [Available from: http://www.gov.cn/zhengce/2014-03/16/content_2640075. htm.

72. Foner N. Models of integration in a settler society: caveats and complications in the US case. Patterns Prejudice. 2012;46(5):486-99. 
73. Wang Y. A Study on migrant workers' willingness to settle down in cities-an empirical analysis based on twelve city questionnaires. Popul Stud. 2013;4:19-32.

74. Li Y, Wang R. Urban tolerance and social integration of floating population in China. China's Popul Resour Environ. 2017;27(001):146-54.

75. Zhi-Yi G, Yong-Hua Y. Social integration of floating population in Gansu Province and influencing factors. Urban Problems. 2015;000(005):97-103.

76. Zhang $X$. Study on the influence of health security on the long-term residence intention of floating population [A master's degree]: Hebei University of Economics and Business. 2020.

77. Li H. The importance of resident health record management. Public health administration in China. 2014;030(005):659.

78. Zhang M. SEM based analysis on the influencing factors of the utilization of basic public health services of floating population in Jilin Province [A master's degree]: Jilin university; 2019.

79. Dahlberg M, Eklof M, Fredriksson P, Jofre-Monseny J. Estimating preferences for local public services using migration data. Urban Studies. 2012;49(2):319.

80. Chen Y. The influence of urban public services on the willingness of migrant workers to stay in cities and settle down [A master's degree]: Nanjing university. 2019.

81. Gan X, Li Y. The Influence of urban Basic Public Services on the new Generation of Migrant Workers' willingness to settle down - An empirical Study based on generalized Hierarchical linear Model. Guizhou Soc Sci. 2019;000(004):126-33.

82. Davies AA, Blake C, Dhavan P. Social determinants and risk factors for non-communicable diseases (NCDs) in South Asian migrant populations in Europe. Asia Eur J. 2011;8(4):461-73.
83. Abbas M, Aloudat T, Bartolomei J, Carballo M, Durieux-Paillard S, Gabus $L$, et al. Migrant and refugee populations: a public health and policy perspective on a continuing global crisis. Antimicrob Resist Infect Control. 2018;7(1):113.

84. Xu C, Wei X, Cui J, Wang X, Xu D. Mixing in regional-structure model about the influence of floating population and optimal control about TB in Guangdong province of China. Int J Biomath. 2017;10(08):1750106.

85. Wang $L$, Wang $L$. The key to preventing and controlling chronic diseases of floating population is to monitor and control related risk factors. Chin J Epidemiol. 2014;35(11):1184-5.

86. Su L, Sun L, Xu L. Review on the prevalence, risk factors and disease management of hypertension among floating population in China during 1990-2016. Glob Health Res Policy. 2018;3(1):24.

87. Kluge HHP, Jakab Z, Bartovic J, D’Anna V, Severoni S. Refugee and migrant health in the COVID-19 response. Lancet. 2020;395(10232):1237-9.

88. Shadmi E, Chen Y, Dourado I, Faran-Perach I, Furler J, Hangoma P, et al. Health equity and COVID-19: global perspectives. Int J Equity Health. 2020;19(1):1-16.

89. Zhou Y, Xu R, Hu D, Yue Y, Li Q, Xia J. Effects of human mobility restrictions on the spread of COVID-19 in Shenzhen, China: a modelling study using mobile phone data. Lancet Digit Health. 2020;2(8):e417-24.

\section{Publisher's Note}

Springer Nature remains neutral with regard to jurisdictional claims in published maps and institutional affiliations.
Ready to submit your research? Choose BMC and benefit from:

- fast, convenient online submission

- thorough peer review by experienced researchers in your field

- rapid publication on acceptance

- support for research data, including large and complex data types

- gold Open Access which fosters wider collaboration and increased citations

- maximum visibility for your research: over $100 \mathrm{M}$ website views per year

At BMC, research is always in progress.

Learn more biomedcentral.com/submissions 